\title{
Amino Acid Metabolism Disorder
}

National Cancer Institute

\section{Source}

National Cancer Institute. Amino Acid Metabolism Disorder. NCI Thesaurus. Code C97090.

An inherited disorder that affects the metabolism of the amino acids. Representative examples include alkaptonuria, homocystinuria, tyrosinemia, and phenylketonuria. 